\title{
Raised plasma cholesterol precursors in patients with gut resections
}

\author{
M A FÄRKKILÄ, R S TILVIS, AND T A MIETTINEN \\ From the Second Department of Medicine, University of Helsinki, Helsinki, Finland
}

SUMmaRY Cholesterol synthesis, faecal bile acids and neutral sterols, and plasma squalene and free and esterified cholesterol precursor sterols concentrations were studied in patients with previous ileal resection $(n=30)$ or jejunoileal bypass $(n=9)$ to elucidate the responses of different cholesterol precursors to enhanced cholesterol synthesis induced by cholesterol and bile acid malabsorption. A subgroup of seven resection patients without fat and bile acid malabsorption served as controls. Of the resection patients, eight had a pure bile acid malabsorption and 15 a combination of fat, bile acid, and modest cholesterol malabsorption. In the patients with jejunoileal bypass, cholesterol and fat absorption was greatly decreased in addition to bile acid malabsorption. The overall cholesterol synthesis was associated with proportionately increased plasma contents of free (and, less consistently, esterified) methyl sterols, the most marked increase, up to 18 times, being recorded for free and esterified lathosterols. The concentrations of the precursor sterols were similarly increased in the subjects with bile acid and cholesterol malabsorption, the two lathosterols showing the highest correlations with the overall cholesterol synthesis $(r=0 \cdot 820-0 \cdot 941)$. In the subjects with jejunoileal bypass cholesterol malabsorption effectively regulated cholesterol synthesis and the precursor levels. Gut exclusions large enough to cause cholesterol and/or bile acid malabsorption activate cholesterol synthesis leading to a proportional elevation in the plasma concentrations of cholesterol precursors, especially in those of lathosterols and free methyl sterols. Determination of the plasma concentration of total lathosterol by a single gas-chromatographic run is a suitable method for rapid screening of clinically significant cholesterol and bile acid malabsorption.

Resection of the small bowel, especially that of the terminal ileum, results in interruption of the enterohepatic circulation of bile acids ${ }^{1-1}$ which, in turn, is associated with low plasma cholesterol concentrations and activated cholesterol synthesis. The overall cholesterol synthesis has been studied in patients with bile acid malabsorption, ${ }^{2-4}$ which in severe cases also leads to cholesterol and fat malabsorption. The effect of cholesterol malabsorption on cholesterol metabolism has been studied mainly in drug treated subjects, however, ${ }^{11-1+1}$ less so in patients with intestinal diseases. ${ }^{15}$ it Cholesterol malabsorption is more effective in reducing plasma cholesterol concentrations and may increase cholesterol synthesis less than does bile acid malabsorption. ${ }^{1+16}$

Address for correspondence: Professor Tatu A Miettinen, Second Department of Medicine, University of Helsinki, Haartmaninkatu 4, SF-(0)290 Helsinki. Finland.

Received for publication 15 July 1987.
The activation of cholesterol synthesis is reflected by an increased release of free methylated cholesterol precursor sterols in plasma probably from the liver. Measurement of these precursor sterols offers a convenient way to assess acute and chronic changes in cholesterol synthesis even in non-steady state of cholesterol metabolism. ${ }^{810-19}$ Plasma squalene fluctuates in a manner parallel to the diurnal variation in cholesterol synthesis, ${ }^{20}$ but it was not a good marker for detecting prolonged changes in cholesterol synthesis ${ }^{81721}$ because the cyclisation of squalene to lanosterol is only weakly rate limiting and, further, may be an adaptive step. The responses of esterified plasma methyl sterols and the later precursors in the synthetic pathway of Figure 1 - that is, demethylated precursor sterols such as lathosterols and desmosterol, to enhanced cholesterol synthesis have not been fully studied, and only preliminary results are available about patients with ileal dysfunction and 


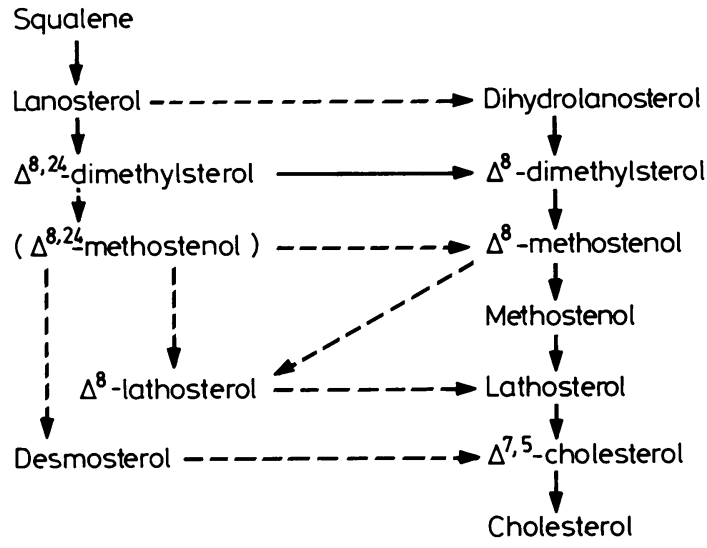

Fig. 1 Proposed conversion of squalene to cholesterol in man. Major pathways as indicated by high plasma precursor contents illustrated with continuous lines, the minor and hypothetical ones with broken line arrows.

cholesterol malabsorption. ${ }^{22}$ It is interesting to note that plasma lathosterols are only weakly increased by squalene feeding induced activation of cholesterol synthesis even though the methylsterol concentrations are markedly increased. ${ }^{19}$ In the present study we measured the overall cholesterol synthesis by the sterol balance technique and quantified free and esterified cholesterol precursors in plasma of patients with jejunoileal bypass and different lengths of ileal resection. Our aim was to answer the following questions: (1) Are the responses of the free methylated and demethylated cholesterol precursor sterols similar to enhanced cholesterol synthesis? (2) Are the responses of esterified precursor sterols comparable with those of the free ones? (3) Are the changes in cholesterol synthesis, evaluated with either the sterol balance technique or by plasma precursor levels, similar in cholesterol and bile acid malabsorption?
Methods

PATIENTS

Thirty nine patients who underwent an ileal resection or bypass were selected from the patient register of the University Hospital of Helsinki (Table 1). Nine patients had undergone jejunoileal bypass (JIB) for intractable obesity four to 10 years ago and had the function of $20 \mathrm{~cm}$ of the proximal jejunum and $25 \mathrm{~cm}$ of the distal ileum. All of them were still obese [BMI $\left.103 \cdot 6(28 \cdot 3) \mathrm{kg} \mathrm{m}^{-2}\right]$. Fifteen patients were operated for Crohn's disease, eight for ileal obstruction, and two patients had had embolism in the superior mesenteric artery. The remaining five patients underwent surgery for diverticulum Meckeli, peritonitis as a result of appendicitis, ovarian endometriosis, intraabdominal herniation and sarcoma of the caecum. The duration since operation varied from three months to 30 years. The length of the small intestine still functioning was estimated on the basis of measurements taken by the surgeon at the operation.

\section{EXPERIMENTAL PROCEDURES}

The patients visited the outpatient clinic and were instructed to maintain their customary home diet and to keep a complete record of food and beverage intake for seven days. These food consumption data were used to determine the mean daily intake of nutrients. ${ }^{23}$ Fractional cholesterol absorption was measured by the method of Crouse and Grundy. ${ }^{24}$ For the determination of faecal fat, faecal neutral sterols and the degree of bile acid and cholesterol malabsorption the patients undertook a three day stool collection at the end of the seven day dietary recall. For this purpose the patients took a capsule containing $0.11 \mu \mathrm{Ci}{ }^{14} \mathrm{C}$-cholesterol, $0.14 \mu \mathrm{Ci}{ }^{3} \mathrm{H}$ beta-sitosterol and $200 \mathrm{mg}$ chromic oxide three times a day with each major meal for the seven days. The fractional cholesterol absorption was calculated by

Table 1 Clinical data of the patients

\begin{tabular}{|c|c|c|c|c|}
\hline Variables & $I R$ & $I R B M$ & $I R F B M$ & $J I B$ \\
\hline $\begin{array}{l}\text { Number } \\
\text { Women/men } \\
\text { Age, years }\end{array}$ & $\begin{array}{ll}7 & \\
6 / 1 & \\
52 \cdot 0 & (6 \cdot 5)\end{array}$ & $\begin{array}{rr}8 & \\
4 / 4 & \\
47 \cdot 0 & (8 \cdot 5)\end{array}$ & $\begin{array}{ll}15 & \\
9 / 6 & \\
47 \cdot 5 & (3 \cdot 6)\end{array}$ & $\begin{array}{l}9 \\
6 / 3 \\
36 \cdot 1 \quad(3 \cdot 2) \ddagger\end{array}$ \\
\hline $\begin{array}{l}\text { Time from operation, years } \\
\text { BMI, } \mathrm{kg} / \mathrm{m}^{2} \\
\text { Weight, } \mathrm{kg} \\
\text { Dietary fat }, \mathrm{g} / \mathrm{kg} / \text { day }\end{array}$ & $\begin{array}{cl}9 \cdot 2 & (2 \cdot 2) \\
23 \cdot 1 & (1 \cdot 2) \\
64 \cdot 6 & (2 \cdot 3) \\
1 \cdot 32 & (0 \cdot 17)\end{array}$ & $\begin{aligned} 7 \cdot 9 & (3 \cdot 4) \\
21 \cdot 7 & (1 \cdot 6) \\
62 \cdot 1 & (5 \cdot 9) \\
1.64 & (0 \cdot 25)\end{aligned}$ & $\begin{aligned} 5 \cdot 4 & (1 \cdot 1) \\
22 \cdot 1 & (1 \cdot 3) \\
62 \cdot 4 & (4 \cdot 4) \\
1 \cdot 61 & (0 \cdot 13)\end{aligned}$ & $\begin{aligned} & 8 \cdot 1(0 \cdot 7) \\
& 35 \cdot 7(2 \cdot 3) \S \\
& 103 \cdot 7(9 \cdot 4) \S \\
& 1 \cdot 02(0 \cdot 11)\end{aligned}$ \\
\hline $\begin{array}{l}\text { Dietary chol, } \mathrm{mg} / \mathrm{kg} / \mathrm{day} \\
\text { Terminal ileum excluded, } \mathrm{cm}^{*} \\
\text { Small bowel left, } \mathrm{cm}\end{array}$ & $\begin{array}{r}6 \cdot 00(0 \cdot 90) \\
49 \cdot 3 \quad(12 \cdot 7) \\
193 \cdot 3 \quad(26 \cdot 7)\end{array}$ & $\begin{array}{cc}6 \cdot 82 & (0 \cdot 91) \\
82 \cdot 1 & (7 \cdot 7) \dagger \\
306 \cdot 7 & (23 \cdot 3) \dagger\end{array}$ & $\begin{array}{rr}7 \cdot 00 & (0 \cdot 60) \\
77 \cdot 3 & (6 \cdot 7)^{\dagger} \\
182 \cdot 0 & (20 \cdot 0)\end{array}$ & $\begin{array}{l}4 \cdot 86(0 \cdot 46) \\
75 \cdot 6(1 \cdot 0) \dagger \\
45 \cdot 5(0 \cdot 6) \S\end{array}$ \\
\hline
\end{tabular}

Mean (SE). ${ }^{*}$ Either proximal, middle or distal part of the last $100 \mathrm{~cm}$ of the terminal ilcum; $\nmid \mathrm{p}<0 \cdot 05 ; \ddagger \mathrm{p}<0 \cdot 01 ; \$ \mathrm{p}<0 \cdot 001$.

IR=ileal resection without fat or bile acid malabsorption; IRBM=ileal resection with bile acid malabsorption; IRFBM=ileal resection with both bile acid and fat malabsorption; JIB = jejunoileal bypass. 
dividing the faecal ${ }^{14} \mathrm{C} /{ }^{3} \mathrm{H}$ ratio by the dietary ${ }^{14} \mathrm{C} /{ }^{3} \mathrm{H}$ ratio.

FAECAL LIPIDS

Faecal fat was determined by the method of van de Kamer et al. ${ }^{25}$ Chromic oxide, used to correct the faecal flow, ${ }^{26}$ was measured by the method of Bolin. ${ }^{27}$ Faecal bile acids and neutral sterols were determined by the gas liquid chromatography (GLC) procedure, ${ }^{2829}$ omitting the thin layer chromatography (TLC), and using a capillary column. ${ }^{30}$ The results are calculated in relation to chromic oxide excretion. Cholesterol synthesis was obtained as the difference between the faecal output of steroids of cholesterol origin (acidic and neutral) and the dietary intake of cholesterol.

After an overnight fast blood samples were drawn into heparinised $10 \mathrm{ml}$ tubes. After sedimentation of red cells at $125 \mathrm{~g}$ plasma cholesterol and triglycerides were determined with standard hospital laboratory methods. ${ }^{3132}$ Plasma squalene, free sterols, and esterified sterols were separated by the TLC and determined by the GLC-method. ${ }^{11222}$ Because the concentration of the lipoproteins transporting cholesterol precursors varied markedly the values are expressed in terms of $\mu \mathrm{g} / \mathrm{mg}$ cholesterol. Liver function was assessed by plasma prothrombin and plasma albumin concentrations.

STATISTICAL ANALYSIS

The differences in the data between the groups were tested with the analysis of variance (ANOVA). The correlations and stepwise regression analysis of different variables were calculated with a Honeywell Bull computer using BMDP software. ${ }^{33}$

\section{Results}

CHARACTERISTICS OF SUBGROUPS

The study population of 39 subjects was divided into four subgroups according to the type of operation and fat and bile acid malabsorption (Table 1). Group 1 with an ileal resection had faecal fat and bile acid values within the normal limits and served as a control group. About half of the distal $100 \mathrm{~cm}$ of the terminal ileum was still functioning. Group 2 had only $18 \mathrm{~cm}$ of the terminal ileum in function after the resection and had bile acid malabsorption but no steatorrhea mainly because most of the remaining small intestine was functioning. Group 3 had both bile acid malabsorption and steatorrhea because the remaining terminal ileum and whole small gut were short. Group 4 had jejunoileal bypass with only $45 \mathrm{~cm}$ of the small intestine in function. This group had severe fat malabsorption in addition to bile acid malabsorption. Plasma prothrombin concentrations did not differ between the groups but plasma albumin was lowered in group 3.

\section{DIETARY INTAKES}

No significant differences were found in the daily calorie, fat and cholesterol intakes among the different groups when expressed per $\mathrm{kg}$ of body weight (Table 1).

\section{PLASMA LIPIDS}

The concentrations of plasma cholesterol were significantly lower in the three groups with bile acid malabsorption than in the control group (Table 2). On the other hand, the plasma triglyceride concentrations tended to be lower in the controls than in the other groups.

CHOLESTEROL ABSORPTION AND SYNTHESIS The parameters of cholesterol metabolism are presented in Table 2. Fractional cholesterol absorption was similar in the control group $(41 \%)$ and in the group with bile acid malabsorption ( $46 \%$ ) but was impaired somewhat in group $3(20 \%)$ with both bile acid and fat malabsorption and especially in group 4

Table 2 Laboratory data of the patients

\begin{tabular}{|c|c|c|c|c|}
\hline Variables & $I R$ & $I R B M$ & $I R F B M$ & $J I B$ \\
\hline $\begin{array}{l}\text { Pl-cholesterol, } \mathrm{mmol} / \mathrm{l} \\
\text { Pl-triglycerides, } \mathrm{mmol} / \mathrm{l} \\
\text { Pl-albumin, } \mathrm{g} / \mathrm{l} \\
\text { Prothrombin time, } \%\end{array}$ & $\begin{array}{cl}5 \cdot 9 & (0 \cdot 4) \\
0 \cdot 88 & (0 \cdot 08) \\
41 \cdot 1 & (0 \cdot 8) \\
94 \cdot 0 & (12 \cdot 0)\end{array}$ & $\begin{array}{l}4 \cdot 2(0 \cdot 3)^{*} \\
1 \cdot 05(0 \cdot 18) \\
42 \cdot 3 \quad(0 \cdot 7) \\
99 \cdot 0(8 \cdot 0)\end{array}$ & $\begin{array}{c}4 \cdot 1(0 \cdot 3)^{\dagger} \\
1.50(0 \cdot 12)^{\dagger} \\
36 \cdot 5(1 \cdot 5)^{*} \\
102 \cdot 0(4 \cdot 0)\end{array}$ & $\begin{array}{r}3 \cdot 7(0 \cdot 3) \dagger \\
1 \cdot 51(0 \cdot 71) \\
39 \cdot 3(1 \cdot 1) \\
101 \cdot 0(6 \cdot 0)\end{array}$ \\
\hline $\begin{array}{l}\text { Faecal fat, } \mathrm{g} / \text { day } \\
\text { Faecal neutral sterols, } \mathrm{mg} / \mathrm{kg} / \mathrm{d} \\
\text { Faecal bile acids, } \mathrm{mg} / \mathrm{kg} / \mathrm{d}\end{array}$ & $\begin{aligned} 5 \cdot 3 & (0 \cdot 6) \\
10 \cdot 8 & (1 \cdot 1) \\
6 \cdot 0 & (0 \cdot 8)\end{aligned}$ & $\begin{aligned} 5 \cdot 3 & (0 \cdot 7) \\
9 \cdot 0 & (0 \cdot 8) \\
36 \cdot 7 & (9 \cdot 4) \dagger\end{aligned}$ & $\begin{array}{ll}26 \cdot 8 & (5 \cdot 7)^{*} \\
13 \cdot 7 & (1 \cdot 3) \\
50 \cdot 7 & (6 \cdot 7) \ddagger\end{array}$ & $\begin{array}{ll}62 \cdot 9 & (13 \cdot 5) \dagger \\
17 \cdot 2 & (2 \cdot 0)^{*} \\
25 \cdot 3 & (3 \cdot 2) \ddagger\end{array}$ \\
\hline $\begin{array}{l}\text { Fractional chol abs, } \% \\
\text { Cholesterol synthesis, } \mathrm{mg} / \mathrm{kg} / \text { day }\end{array}$ & $\begin{array}{l}41 \cdot 3(4 \cdot 0) \\
10 \cdot 8(1.9)\end{array}$ & $\begin{array}{ll}46 \cdot 4 & (2 \cdot 4) \\
42 \cdot 2 & (10 \cdot 0) \dagger\end{array}$ & $\begin{array}{ll}20 \cdot 4 & (4 \cdot 1) \dagger \\
57 \cdot 4 & (7 \cdot 2) \ddagger\end{array}$ & $\begin{array}{rr}8 \cdot 1 & (3 \cdot 1) \ddagger \\
37 \cdot 7 & (4 \cdot 5) \ddagger\end{array}$ \\
\hline
\end{tabular}

${ }^{*} \mathrm{p}<0.05 ; \nmid \mathrm{p}<0.01 ; \neq \mathrm{p}<0.001$.

For abbreviations see Table 1 .

Conversion factor for cholesterol $(\mathrm{mg} / \mathrm{dl})$ is 38.7 and for triglycerides $(\mathrm{mg} / \mathrm{dl}) 88 \cdot 5$. 


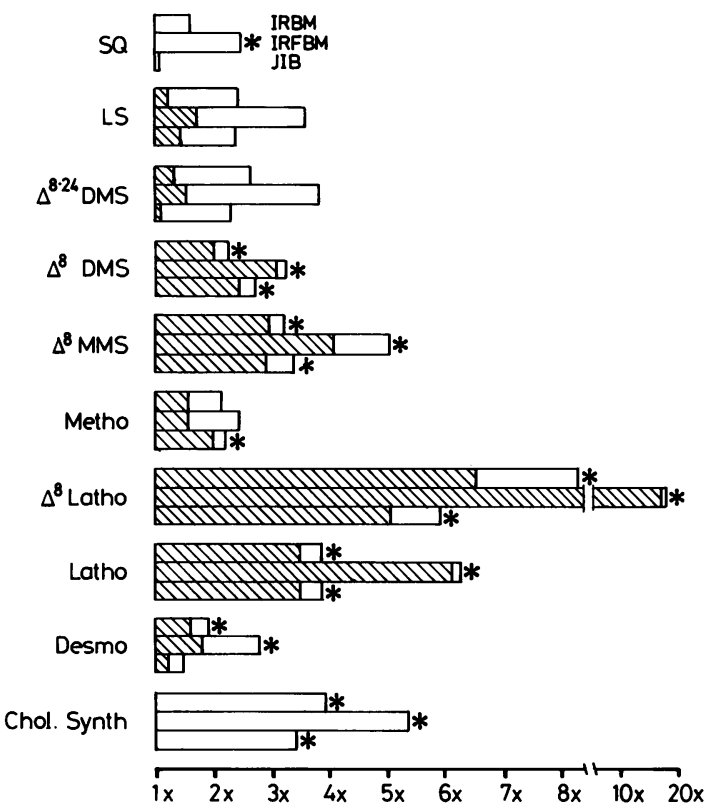

Fig. 2 Plasma free and esterified cholesterol precursors and cholesterol synthesis in patients with pure bile acid malabsorption (IRBM), combination of both (IRFBM), or mainly cholesterol malabsorption (JIB) divided by those of operated controls. Free precursors are shown by continuous columns, esterified by shaded ones. All the free sterol precursor ratios were significantly increased in IRBM, IRFBM and JIB as compared with controls. Statistics are shown for the ester precursor ratios. ${ }^{*} p<0 \cdot 05 . S q=$ squalene; Metho=methosterol; Lano=lanosterol; $\triangle^{8}$ Latho $=$ $\triangle^{8}$ lathosterol; $\triangle^{8,24} \mathrm{DMS}=\triangle^{8,24}$ dimethyl $(4 \alpha 4 \beta)$ sterol; Latho=lathosterol; $\triangle^{8} D M S=\triangle^{8}$ dimethyl $(4 \alpha 4 \beta)$ sterol; Desmo = desmosterol; $\triangle^{8} M M S=\triangle^{8}$ monomethyl $(4 \alpha)$ sterol; Chol $=$ cholesterol .

with jejunoileal bypass ( $8 \%$ ). In the latter two groups the faecal neutral sterol excretion was also increased, and the absolute absorption of dietary cholesterol was clearly lower $(1.4$ and $0.4 \mathrm{mg} / \mathrm{kg} /$ day $)$ than in other groups $(2 \cdot 6-3 \cdot 1 \mathrm{mg} / \mathrm{kg} /$ day $)$. When compared with the controls, the overall cholesterol synthesis was increased by a factor of three to five in groups 2 and 4 , however, most significantly in group 3 although with reduced plasma albumin concentrations. Despite the markedly short functioning small gut, continuing obesity, and marked cholesterol malabsorption of the jejunoileal bypass patients, their cholesterol synthesis was increased less $(p<0.05)$ than in resection group 3 with a combination of bile acid, fat, and moderate cholesterol malabsorption.

FREE CHOLESTEROL PRECURSORS IN PLASMA The contents of plasma squalene and free and esterified methyl sterols, demethylated C-27 pre- cursor sterols and cholesterol are presented in relation to the operated control group, in Figure 2. The concentration of plasma squalene was significantly increased only in group 3 . The free precursor sterol contents were 3-18, 2-7 and 1.4-6 times higher in groups 3,2 and 4, respectively, than in the operated controls. The increases in the precursor sterol concentrations were mainly related to the respective increases in overall cholesterol synthesis no matter whether the synthesis was stimulated by pure bile acid malabsorption alone (group 2) or combined with cholesterol malabsorption (groups 3 and 4). The highest relative rise (Fig. 2) was found for free $\triangle^{8}$-lathosterol, followed by lathosterol, $\Delta^{8}$ methostenol and $\triangle^{8.24}$ dimethylsterols $(6-18,4-6$, 3-5 and 2-3 times, respectively). Desmosterol and methostenol were increased only moderately. In absolute terms the highest increases were found for lathosterol (from 235 to $146010^{2} . \mu \mathrm{mol} / \mathrm{mmol}$ ) and $\triangle^{8}$-lathosterol (from 10 to $18610^{2} . \mu \mathrm{mol} / \mathrm{mmol}$ ).

ESTERIFIED PRECURSOR STEROLS

The responses of the esterified $\triangle^{8}$-dimethyl and $\triangle^{8}$-monomethyl sterols and lathosterols levels were similar to the respective free sterols so that the esterification percentage was unchanged (Fig. 2). Esterified lanosterol, $\triangle^{8.24}$ dimethylsterol, methostenol and desmosterol, however, responded poorly and inconsistently to the enhanced cholesterol synthesis.

FACTORS DETERMINING PRECURSOR CONCENTRATIONS

Table 3 shows that all the free plasma cholesterol precursors, except squalene, were significantly correlated with cholesterol synthesis when the data of all operated subjects were plotted together. The correlations were less significant for the esterified methyl sterols and negative for the esterification percentages. The highest correlations $(r=0 \cdot 820-$ 0.941 ) were found for the free, esterified and total values of the two lathosterols. Factors possibly associated with the plasma concentrations of cholesterol precursors were further studied using stepwise regression analysis of eight variables separately for jejunoileal bypass and for patients with ileal resections. The results are shown for total $\triangle^{8}$ lathosterol only (Table 4). In jejunoileal bypass $\triangle^{8}$ lathosterol correlated strongly negatively with cholesterol absorption (both fractional and absolute) and positively with bile acid output. When cholesterol absorption entered the stepwise regression analysis no further significant correlations were found with $\triangle^{8}$-lathosterol (step 1), suggesting that cholesterol malabsorption was the major factor which stimulated cholesterol synthesis and subsequently increased the 
Table 3 Correlations of plasma cholesterol and its precursors ( $\mu \mathrm{g} / 100 \mathrm{mg}$ cholesterol) with cholesterol synthesis ( $m g / k g /$ day)

\begin{tabular}{|c|c|c|c|c|}
\hline Precursor & Free & Ester & Total & Esterification \% \\
\hline Squalene & $0 \cdot 178$ & - & $0 \cdot 178$ & - \\
\hline Lanosterol & $0.671 \ddagger$ & $0.495 \ddagger$ & $0 \cdot 682 \ddagger$ & $-0 \cdot 273$ \\
\hline$\Delta^{8,24}$ dimethyl $(4 \alpha, 4 \beta)$ sterol & $0 \cdot 761 \ddagger$ & $0 \cdot 123$ & $0 \cdot 765 \ddagger$ & $-0 \cdot 350^{*}$ \\
\hline$\triangle^{8}$ dimethyl $(4 \alpha, 4 \beta)$ sterol & $0.797 \ddagger$ & $0.646 \ddagger$ & $0.799 \ddagger$ & $-0 \cdot 108$ \\
\hline$\Delta^{8}$ monomethyl $(4 \alpha)$ sterol & $0.795 \ddagger$ & $0 \cdot 610 \ddagger$ & $0 \cdot 783 \ddagger$ & $-0 \cdot 160$ \\
\hline Methosterol & $0 \cdot 688 \ddagger$ & $0 \cdot 178$ & $0 \cdot 640 \ddagger$ & $-0 \cdot 374^{*}$ \\
\hline Lathosterol & $0 \cdot 824 \ddagger$ & $0.851 \ddagger$ & $0 \cdot 841 \ddagger$ & $-0 \cdot 156$ \\
\hline Desmosterol & $0 \cdot 641 \ddagger$ & $0.478+$ & $0.640 \ddagger$ & $-0 \cdot 546 \ddagger$ \\
\hline Cholesterol & -0.435 & -0.428 & $-0 \cdot 444^{*}$ & $0 \cdot 147$ \\
\hline
\end{tabular}

${ }^{*} \mathrm{p}<0.05 ; \dagger \mathrm{p}<0.01 ; \neq \mathrm{p}<0.001$.

plasma concentrations of the cholesterol precursors in the patients with jejunoileal bypass.

A similar analysis for the patients with ileal resections (Table 4) revealed that bile acid malabsorption, caused by ileal dysfunction, was the major factor increasing the plasma precursor concentrations through enhanced cholesterol synthesis. Bile acid malabsorption in the regulation of the plasma concentrations of the cholesterol precursor sterols was also identified as playing a decisive role when group 3 with combined bile acid and cholesterol malabsorption, and group 2 with pure bile acid malabsorption were analysed separately (data not shown).

\section{Discussion}

\section{METHYL STEROLS V LATHOSTEROLS}

The main factors determining the plasma concentrations of a single cholesterol precursor are the synthesis rate, the rate of further conversion to cholesterol, and the release to and removal from plasma. The present study showed that of the cholesterol precursors the chronic stimulation of cholesterol synthesis by different types of ileal resections or jejunoileal bypass clearly increased the plasma concentrations of lathosterols, especially $\triangle^{8}$-lathosterol, more effectively than those of squalene, methylsterols or demosterol. Short term stimulations of cholesterol synthesis increase the plasma concentrations of squalene, lanosterol and $\Delta^{8.24}$ dimethylsterols relatively more than those of the later methylated precursors ${ }^{819}$ whereas more chronic stimulation reverses this relation, probably as a result of adaptation in further conversion of squalene and lanosterol. ${ }^{174}$ The present findings suggest that the enhanced metabolism of the methyl sterols (Fig. 1) leads to accumulation of the later intermediates, $\triangle^{8}$-methostenol, $\triangle^{8}$-lathosterol and lathosterol, and that their further conversion to cholesterol becomes more rate limiting during chronically stimulated cholesterol synthesis. The significance of the high concentrations of these sterols in the feedback inhibition of cholesterol synthesis is not known at the moment.

Table 4 Correlation of eight variables with total plasma content of $\triangle^{8}$-lathosterol in patients with gut exclusions. Stepwise regression analysis

\begin{tabular}{|c|c|c|c|c|}
\hline \multirow[b]{2}{*}{ Variable } & \multicolumn{2}{|l|}{ Step 0} & \multicolumn{2}{|c|}{ Step 1} \\
\hline & $\begin{array}{l}J I B \\
n=9\end{array}$ & $\begin{array}{l}\text { Ileal resection } \\
n=30\end{array}$ & $J I B$ & Ileal resection \\
\hline Body mass index, $\mathrm{kg} \mathrm{m}^{-2}$ & NS & NS & NS & NS \\
\hline Dietary fat, g/day & NS & NS & NS & NS \\
\hline Fractional cholesterol absorption, \% & $-0.746 \dagger$ & $-0 \cdot 521 \ddagger$ & NS & NS \\
\hline Dietary cholesterol absorbed, mg/day & $-0.779 \ddagger$ & NS & - & NS \\
\hline Plasma cholesterol, $\mathrm{mmol} / \mathrm{l}$ & $-0 \cdot 607^{*}$ & $-0 \cdot 497 \ddagger$ & NS & NS \\
\hline Fecal bile acids, $\mathrm{mg} / \mathrm{kg} / \mathrm{day}$ & $0 \cdot 632^{*}$ & $0 \cdot 860 \ddagger$ & NS & - \\
\hline Fecal neutral steroids, $\mathrm{mg} / \mathrm{kg} /$ day & NS & $0.413^{*}$ & NS & NS \\
\hline Fecal fat, $\mathrm{g} / \mathrm{kg} / \mathrm{day}$ & NS & $0 \cdot 385^{*}$ & NS & NS \\
\hline
\end{tabular}

$\mathrm{JIB}=$ jejunoileal bypass; NS = not significant Step $1=$ the variable with highest correlation in both groups entered the analysis. ${ }^{*} \mathrm{p}<0.05 ; \mathrm{tp}<0.01 ; \neq \mathrm{p}<0.001$. 
Is then, the huge relative increase of $\triangle^{8}$-lathosterol an actual measure of increased cholesterol synthesis overall or only in some tissue - for example, in the liver? The current concept implies that bile acid malabsorption enhances cholesterol conversion to bile acids in the liver depleting hepatocyte cholesterol which, in turn, activates hepatic cholesterol synthesis, upregulates hepatic LDL apoB receptors and subsequently lowers plasma cholesterol through enhanced receptor mediated cataboalism of LDL. ${ }^{35}$ As these changes are supposed to take place mainly in the liver, the increase in overall cholesterol synthesis and in cholesterol precursor concentrations should also be mainly of hepatic origin. In fact, the plasma contents of cholesterol precursors in man exhibit a high correlation (r-value up to 0.941 ) with hepatic hydroxymethyl glutaryl CoA reductase activity, ${ }^{36}$ the key enzyme in regulation of cholesterol synthesis. The relative six to 18 -fold increases of $\triangle^{*}$-lathosterol in different groups were actually higher than the respective three to five fold increases in overall synthesis. Thus, the huge increase in the plasma concentration of $\triangle^{8}$-lathosterol may mainly reflect the actual change in hepatic cholesterol synthesis. The marked accumulation of $\triangle^{8}$-lathosterol is unexpected because at least in the rat liver, the conversion of $\Delta^{8}$ to $\Delta^{7}$ by steroid-8-ene isomerase is 10 times more active than methyl sterol oxidase. ${ }^{37}$

\section{ESTERIFIED PRECURSOR STEROLS}

The inconsistent responses of the esterified precursors sterols to enhanced cholesterol synthesis that is, the poor increase of methyl sterols and the high increase of lathosterols, are mostly explainable by their different esterification: (1) Methyl sterols are not esterified in plasma by lecithin cholesterol acyl transferase (LCAT). ${ }^{38}$ Thus, an increase in the plasma concentration of free methyl sterols is not automatically followed by an increase in that of esterified methyl sterols. (2) Methyl sterol esters are formed in tissues most likely in the liver mainly by acyl-coenzyme A: cholesterol acyl transferase $(\text { ACAT })^{39}$ t) and are apparently secreted in VLDL into the blood. Only monomethylsterols, not dimethylsterols, are effectively esterified by this enzyme. ${ }^{+1}$ This would explain the low plasma values for the tri- and dimethylsterols and the clearly higher baseline values for the two methostenols. Thus, the plasma concentrations of esterified methylsterols depend mainly on methyl sterol balance and ACAT activity in hepatocytes. (3) Demethylated cholesterol precursors are substrates for both ACAT and LCAT. ${ }^{+1+11}$ Accordingly, in contrast with the methyl sterols, an increase in the plasma concentration of free demethyl sterols results in their esterification by LCAT and thus in a proportionate increase in the esterified forms. The findings in Figure 2 are actually compatible with this consideration.

CHOLESTEROL AND BILE ACID MAIABSORPTION The increase in the cholesterol precursor concentrations was proportionately similar to the enhanced cholesterol elimination caused either by cholesterol or bile acid malabsorption. In coeliac disease, however, the pure cholesterol malabsorption increases cholesterol precursor sterol concentrations relatively less than does bile acid malabsorption. ${ }^{\text {in }}$ Similar results have been obtained with neomycin induced cholesterol malabsorption when the increase in cholesterol synthesis is relatively small, however. ${ }^{34}$ Stepwise regression analysis in jejunoileal bypass (Table 4) emphasises the importance of cholesterol absorption in the regulation of cholesterol metabolism, an aspect that has been accorded too little attention so far. In the resection patients bile acid malabsorption is, correspondingly, the fundamental factor in enhanced synthesis and reduced plasma cholesterol concentrations.

CLINICAL USE OF CHOLESTEROL PRECURSORS The high correlation between the total plasma con-

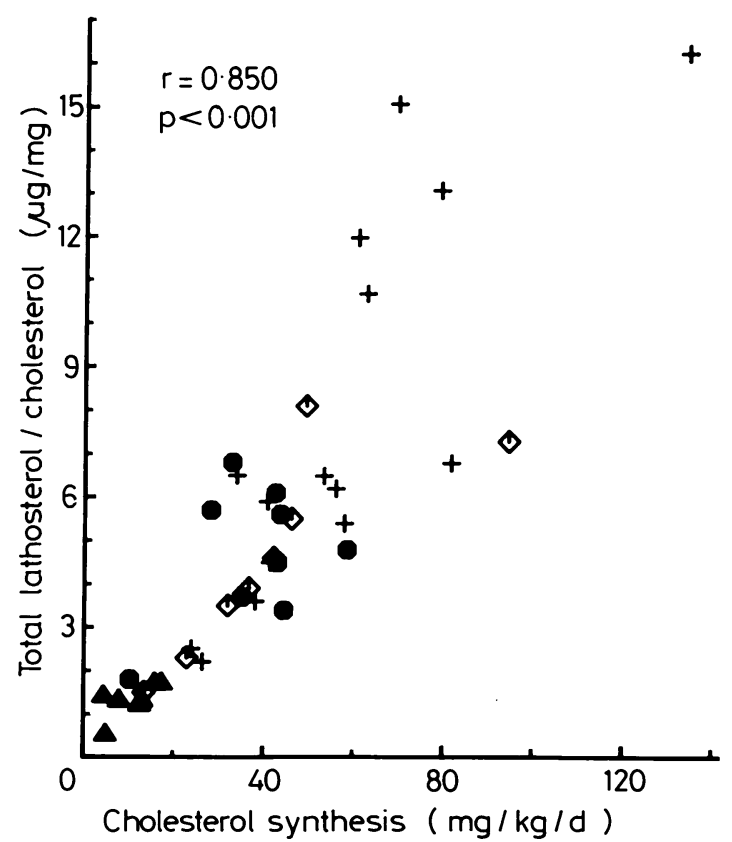

Fig. 3 Correlation of total plasma lathosterol ( $\mu \mathrm{g} / \mathrm{mg}$ of cholesterol) with cholesterol synthesis in patients with gut exclusions. $\mathbf{\Delta}=$ operated control patients, $\diamond=$ patients with ileum resection causing bile acid malabsorption, $+=$ patients with intestinal resection causing bile acid, fat and cholesterol malabsorption, = patients with jejunoileal bypass with bile acid, fat and cholesterol malabsorption. 


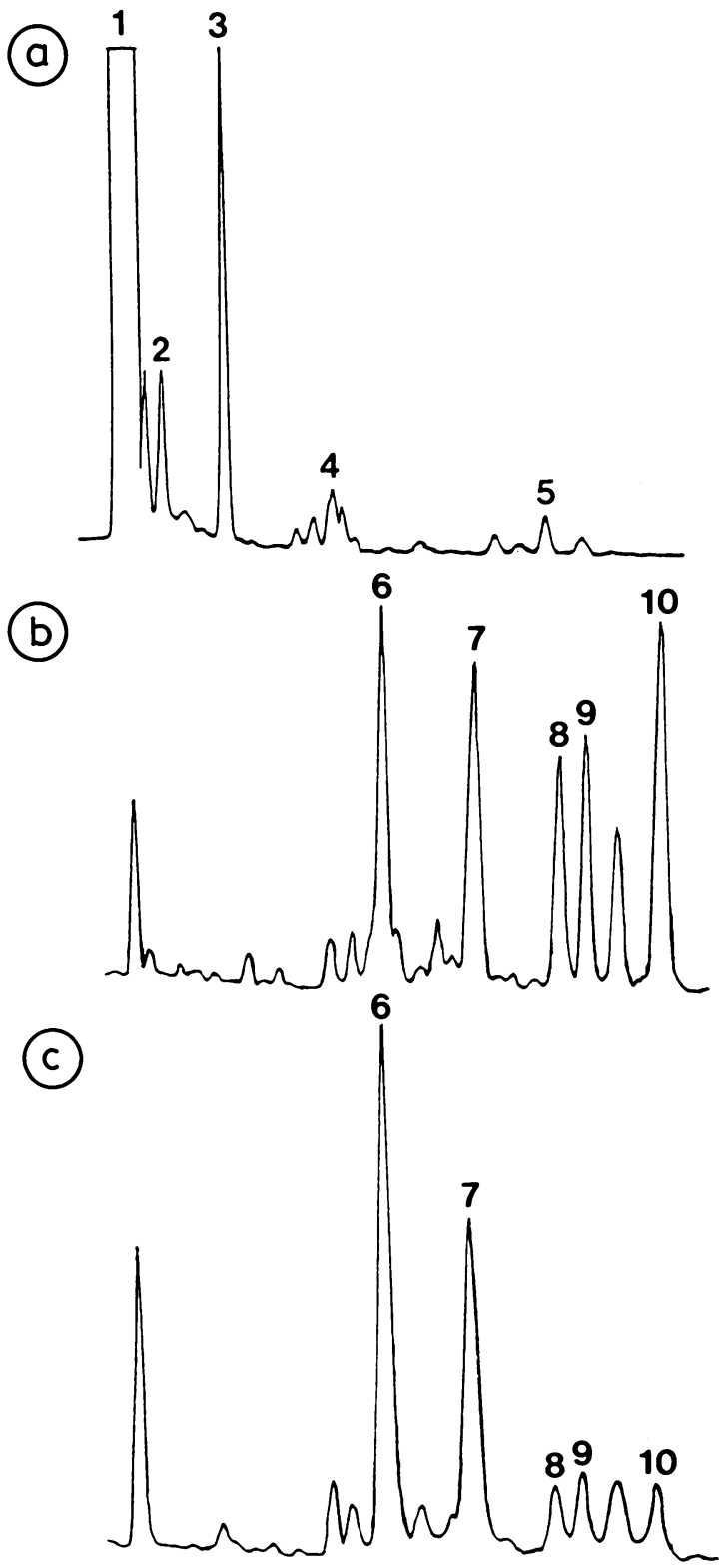

Fig. 4 Gas chromatographic run of (a) free cholesterol fraction including peaks for demethylated precursor sterols and (b) free and (c) esterified methylsterols. The peaks are identified on the basis of their retention times. $1=$ chol, $2=$ $\triangle^{8}$ latho, $3=$ latho, $4=$ campesterol, $5=\beta$-sitosterol, $6=$ $\triangle^{8} M M S, 7=$ metho, $8=\triangle^{8} D M S, 9=$ lano, $10=\triangle^{8.24} D M S$.

For abbreviations see Fig. 2.

tent of lathosterols and cholesterol synthesis induced either by impaired cholesterol or bile acid absorption suggests that the determination of plasma lathosterol can be used to screen patients with diarrhoea for clinically significant cholesterol or bile acid malabsorption. The findings in Figure 3 indicate that $95 \%$ of cases with an intestinal exclusion large enough to enhance cholesterol synthesis had increased plasma lathosterol concentrations. Because the plasma lathosterol concentration is high enough to allow accurate measurement, it can be determined easily and quickly with a single GLC run on a capillary column directly from non-saponifiable plasma lipids, Figure 4. Low base line concentrations of methyl sterols require time consuming preliminary TLC isolation before GLC quantification..$^{22}$

Mmes Eeva Gustafsson, Leena Kaipainen, Liisa Kuhta, Pia Hoffström, Anja Salolainen, Marja Aarnio and Heli Vainio are acknowledged for their technical and secretarial help. This study was supported by a grant from the Scientific Foundation of the Orion Pharmaceutical Company and the Yrjö Jahnsson Foundation.

\section{References}

1 Fromm H, Hofmann AF. The importance of bile acids in human diseases. Adv Intern Med 1975; 37: 144-92.

2 Grundy SM, Hofmann AF, Davignon J, et al. Human cholesterol synthesis is regulated by bile acids. J Clin Invest 1966; 45: 1018-9.

3 Moutafis CD, Myant NB, Tabagchali S. The metabolism of cholesterol after resection or by-pass of the lower small intestine. Clin Sci 1968; 35: 537-45.

4 Miettinen TA. Relationship between faecal bile acids absorption of fat and vitamin $\mathrm{B}_{12}$ and serum lipids in patients with ileal resections. Eur J Clin Invest 1971; 1: 452-60.

5 Buchwald H, Moore RB, Varco RL. Surgical treatment of hypercholesterolemia. Circulation 1974; 49: 1-37.

6 Grundy SM, Ahrens EH, Salen G. Interruption of enterohepatic circulation of bile acids in man: Comparative effects of cholestyramine and ileal exclusion on cholesterol metabolism. J Lab Clin Med 1971; 78: 94-121.

7 Ho KJ, Bond JL. Cholesterol metabolism in patients with resection of ileum and proximal colon. Am J Clin Nutr 1977; 30: 151-9.

8 Miettinen TA. Detection of changes in human cholesterol metabolism. Ann Clin Res 1977; 2: 300-320.

9 Krag E, Hojgaard L. Bile acid metabolism after intestinal bypass operations. Int J Obesity 1981; 5: 519-25.

10 Grundy SM, Ahrens EH Jr, Davignon J. The interaction of cholesterol absorption and cholesterol synthesis in man. J Lipid Res 1969; 10: 304-15.

11 Crouse JR, Grundy SM. Effects of sucrose polyester on cholesterol metabolism in man. Metabolism 1979; 28: 994-1000.

12 Sedaghat A, Samuel P, Crouse JR, et al. Effects of neomycin on absorption, synthesis and/or flux of cholesterol in man. J Clin Invest 1975; 55: 12-21.

13 Lees AM, Mok HYI, Lees RS, et al. Plant sterols as cholesterol-lowering agents: Clinical trials in patients with hypercholesterolemia and studies of sterol balance. Atherosclerosis 1977; 28: 325-38. 
14 Miettinen TA. Effects of neomycin alone and in combination with cholestyramine on serum cholesterol and fecal neutral steroids in hypercholesterolemic subjects. J Clin Invest 1979; 64: 1485-93.

15 Vuoristo M, Miettinen TA. Cholesterol absorption, elimination and synthesis in coeliac disease. Eur J Clin Invest 1982; 12: 285-91

16 Vuoristo M, Miettinen TA. Serum cholesterol precursor sterols in coeliac disease: effects of glutein free diet and cholestyramine. Gut 1986; 27: 1312-9.

17 Miettinen TA. Cholesterol precursors and their diurnal rhythm in lipoproteins of patients with jejuno-ileal bypass and ileal dysfunction. Metabolism 1985; 34: 425-30.

18 Miettinen TA. Serum squalene and methyl sterols as indicators of cholesterol synthesis in vivo. Life Sci 1969; 8: 713-21.

19 Miettinen TA. Precursor sterols related to cholesterol synthesis. In: Sanghvi A, ed. Proceedings of the NATO meeting, coordinate regulation of cholesterol metabolism. Santa Fe, University of Pittsburgh School of Medicine, PA. 1985: 87.

20) Miettinen TA. Diurnal variation of cholesterol precursors squalene and methylsterols in human plasma lipoproteins. J Lipid Res 1982; 23: 466-73.

21 Liu GCK, Ahrens EH Jr, Schriebman PH, et al. Measurement of squalene in human tissue and plasma: validation and application. J Lipid Res 1976; 17: 38-45.

22 Miettinen TA, Koivisto P. Non-cholesterol sterols and bile acid production in hypercholesterolaemic patients with ileal bypass. In: Paumgartner G, Stiehl A, Gerok $\mathrm{W}$, eds. Bile acids and cholesterol in health and disease. Lancaster, MTP, 1983: 183-7.

23 Ahlström J, Räsänen L, Kuvaja K. A method of data processing for food consumption surveys. A IV Biologica. Ann Acad Sci Fenn 1972; 194: 1-8.

24 Crouse JR, Grundy SM. Evaluation of a continuous isotope feeding method for measurement of cholesterol absorption in man. $J$ Lipid Res 1978; 19: 967-71.

25 van de Kamer JH, ten Bokkel Huinink H, Weyers HA. Rapid method for the determination of fat in faeces. J Biol Chem 1949; 177: 347-55.

26 Davignon J, Simmonds WJ, Ahrens EH Jr. Usefulness of chromic oxide as an internal standard for balance studies in formula-fed patients and for assessment of colonic function. J Clin Invest 1968; 47: 127-38.

27 Bolin DW, King RP, Klosterman EH. A simplified method for determination of chronic oxide $\left(\mathrm{Cr}_{2} \mathrm{O}_{3}\right)$ when used as an index substance. Science 1952; 116: 634-5.
28 Miettinen TA, Ahrens EH Jr, Grundy SM. Quantitative isolation and gas-liquid chromatographic analysis of total dietary and fecal neutral steroids. J Lipids Res 1965; 6: 411-24.

29 Grundy SM, Ahrens EH Jr, Miettinen TA. Quantitative isolation and gas-liquid chromatographic analysis of total fecal bile acids. J Lipid Res $1965 ;$ 6: 397-410.

30 Miettinen TA. Gas-liquid chromatographic determination of fecal neutral sterols using a capillary column. Clin Chem Acta 1982; 124: 245-8.

31 Röschlau P, Bernt E, Gruber W. Enzymatische Bestimmung des Gesamt Cholesterius in Serum. $Z$ Klin Biochem 1974; 12: 403-7.

32 Wahlefeld AW. Triglyceride determination after enzymatic hydrolysis. In: Bergmayer, ed. Methods in enzymatic analysis. New York, Academic Press, 1974; 5: $1831-5$.

33 University of California, Los Angeles. BMDP. Statistical software. Los Angeles, University California Press, 1981.

34 Miettinen TA. Effects of neomycin alone and in combination with cholestyramine on serum methyl sterols and conversion of acetate mevalonate to cholesterol Scand J Clin Lab Invest 1982; 42: 189-96.

35 Goldstein JL, Brown MS. Progress in understanding the LDL receptor and $\mathrm{HMG}-\mathrm{COA}$ reductase, two membrane proteins that regulate the plasma cholesterol. J Lipid Res 1984; 25: 1450-61.

36 Björkhem I, Miettinen TA, Reihner E, Angelin B, Ewerth S, Einarsson K. High correlation between serum levels of some cholesterol precursors and activity of HMG CoA reductase in human liver. J Lipid Res 1987; 28: 1137-43.

37 Yamaga N, Gaylor JL. Characterization of microsomal steroid-8-ene isomerase of cholesterol biosynthesis. J Lipid Res 1978; 19: 375-82.

38 Tilvis RS, Miettinen TA. A lack of esterification of lanosterols and other methylsterols in human serum in vitro. Scand J Clin Lab Invest 1980; 40: 671-4.

39 Brady DR, Gaylor JL. Enzymatic formation of esters of methyl sterol precursors of cholesterol. J Lipid Res 1971; 12: 270-6.

40 Tavani DM, Nes WR, Billheimer JT. The sterol substrate specificity of acyl CoA: cholesterol acyl transferase form rat liver. J Lipid Res 1982; 23: 774-81.

41 Nordby G, Norum K. Substrate specificity of lecithin: cholesterol acyltransferase, esterification of desmosterol, $\beta$-sitosterol and cholesterol in human plasma. Scand J Clin Lab Invest 1975; 35: 97-101. 